\title{
VARIATION IN SOME HAEMATOLOGICAL PARAMETERS, IRON AND LEAD LEVELS IN WORKERS EXPOSED TO ELECTRONIC WASTE IN BENIN CITY, NIGERIA
}

\author{
Osaretin Godwin Igharo ${ }^{1,2 *}$, John I. Anetor ${ }^{2}$ Oladele Osibanjo ${ }^{3}$, Micheal Awo \\ Okungbowa $^{1}$, Festus Aigbokheo Idomeh ${ }^{1}$ and Tracy Oshione Aleoghena ${ }^{1}$
}

${ }^{1}$ Department of Medical Laboratory Sciences, School of Basic Medical Sciences, College of Medical Sciences, University of Benin, Benin City, Nigeria.

${ }^{2}$ Department of Chemical Pathology, Toxicology and Micronutrient Metabolism Unit, College of Medicine, University of Ibadan, Ibadan, Nigeria.

${ }^{3}$ Department of Chemistry and Basel Convention Coordinating Centre for Training and Technology Transfer for the Africa Region, University of Ibadan, Oyo State, Nigeria.

Corresponding Author: Igharo, Osaretin Godwin

Department of Medical Laboratory Science,

School of Basic Medical Sciences,

College of Medical sciences,

University of Benin,

Benin City, Nigeria.

Email: osaretin.igharo@uniben.edu

Tel: 08038664896

Author Contributions

Conceptualization, Osaretin Igharo and John Anetor; Data curation, Tracy Aleoghena; Funding acquisition, Festus Idomeh; Investigation, Osaretin Igharo; Methodology, Festus Idomeh; Project administration, Oladele Osibanjo and Micheal Okungbowa; Supervision, John Anetor, Oladele Osibanjo and Micheal Okungbowa. 


\begin{abstract}
The volume of electronic waste (e-waste) received in Nigeria is reportedly on the increase and the effects on environmental health are yet to be fully ascertained. This study aimed to investigate haematological indices, lead and serum iron levels in workers occupationally exposed to electronic wastes in South-South, Nigeria. In this pilot study, 104 participants were enrolled from Benin City, South-South Nigeria; consisting of 63 E-waste Workers (EW) sex- and aged-matched with 41 Unexposed Participants (Control). Blood levels $(5 \mathrm{~mL})$ of the metals (lead and iron) were determined using Inductively Coupled Plasma-Mass Spectrometry while the haematological parameters [white blood cells (WBC), Lymphocytes ( LY); monocytes (MO), granulocytes(GR), red blood cells (RBC), haemoglobin ( $\mathrm{Hgb})$, haematocrit (HCT), mean cell volume (MCV), mean cell haemoglobin $(\mathrm{MCH})$, mean cell haemoglobin concentration (MCHC) and platelets (PLT)] were determined using standard methods. Results obtained from this study show a significantly low serum iron $(11.5 \pm 2.14 \mu \mathrm{g} / \mathrm{dL})$ in the EW compared with Control $(168.9 \pm 2.39 \mu \mathrm{g} / \mathrm{dL})$; while blood lead level in EW $(1.07 \pm 0.02 \mu \mathrm{g} / \mathrm{dL})$ was significantly elevated compared with Control $(0.72 \pm 0.12)$. Total WBC and RBC, HCT, MO and MCV were all significantly elevated in EW compared with Control while LY and PLT in the EW were significantly decreased compared with Control. This study concludes that chronic occupational e-waste exposure may increase blood lead level, lower serum iron status and may have adversely altered some important haematological parameters in the studied population.
\end{abstract}

Keywords: Electronic waste, haematotoxicity, lead, occupationally exposed workers. 


\section{Introduction}

Technological advancements in the electronic industry have paved way for the production of several important electronic devices such as lighting equipment; electrical and electronic tools, toys, leisure and sports equipment, medical devices, and automatic dispensers among others. While these devices have made life relatively easier and more comfortable for man, the surge in their production is however, associated with a concomitant increase in the rate of production of electronic wastes, especially in developing countries were they are poorly managed as reports have shown that these wastes usually end up in open dumps and unlined landfills [1]. Electronic and electrical waste (e-waste), also referred to as Waste Electrical and Electronic Equipment (WEEE) is defined as any end-of-life equipment, which is dependent on electrical currents or electromagnetic fields in order to work properly. The core components of most electrical and electronic equipment such as batteries, circuit boards, plastic casings, cathode-ray tubes, activated glass, and lead capacitors are also classified as e-waste [2].

Electronic wastes contain potentially harmful chemical elements which could constitute significant sources of occupational and/or environmental health hazards. Toxic elements frequently found in electronic wastes include lead, cadmium, chromium, mercury, copper, manganese, nickel, arsenic, zinc, iron, and aluminium [3-4]

The pathophysiology of heavy metal toxicity is one of the most studied areas of medical toxicology. Over the years, several plausible explanations on the mechanism of heavy metal toxicity have been put forward; these include oxidative stress [5], lipid peroxidation, metal-metal interaction, enzyme inhibition [6-8], DNA binding [9], damage of antioxidant system [10] and so on. 
Lead toxicity is associated with a number of physiological, morphological, and biochemical alterations such as liver dysfunction [11], haematological disorders [12], impairment of renal system functions [13], glucose metabolism abnormality [14], and nervous system disturbances [15]. Unlike Lead which is always harmful whenever it is detected in the human body irrespective of its concentration, iron plays a vital role in several cellular and enzymatic processes in the body. It however, needs to be maintained within certain levels in the body as its deficiency or toxicity could cause disease [16].

The present study seeks to evaluate the effect of lead on iron status and the haematopoietic system as a result of occupational exposure to electronic wastes. 


\section{Materials and methods}

\section{Study Design and Study Area}

This study was designed as a comparative study between occupationally exposed and unexposed groups. The study was carried out in the Metropolitan City of Benin, Edo State located in South-south Nigeria. Benin City is the capital of Edo State, Nigeria.

\section{Exposed Group}

Male Waste Electric and Electronic Equipment (WEEE) Workers ( $\mathrm{n}=63$, Mean age of 31 years), working and living in Benin City, formed the exposed group. The states of origin of the exposed subjects comprised Edo, $n=32$ (50.8\%); Imo, $n=15$ (23.8\%); Delta, $n=7$ (11.1\%); Anambra, $n=3$ (4.8\%); Ekiti, $n=2 ;(3.2 \%)$; Enugu, $n=2(3.2 \%)$ and Abia, $n=2(3.2 \%)$. Only subjects with a minimum of 5 years of occupational exposure to toxic substances in WEEE were enrolled into the study.

\section{Inclusion Criteria}

(a) The exposed subjects comprised Electronic Technicians carrying out informal (primitive) e-waste recycling, processing, repair and dismantling repair of electronic and electrical equipment. Subjects who were occupationally exposed to e-waste for a period of five years and above at the time of sample collection were considered suitable for the study. The five years duration of exposure used in this study is based on E-waste Risk Assessment Report of Adaramodu and colleagues [17]. 
(b) Control subjects were healthy male individuals with minimal or no occupational exposure and with no hobby involving e-waste exposure. The non-exposed participants had no previous demographic and medical history of incidence of cancer.

\section{Exclusion Criteria}

E-waste workers who are not exposed to e-waste for a period up to five years at the time of sample collection were considered suitable for the study. Subject with history of any form of cancer, tobacco smoking and alcoholism were excluded from the study. Tobacco smoking and alcohol consumption also served as basis of exclusion for recruiting the apparently healthy control subjects.

\section{Ethical Approval}

The protocol for this study was approved by the Health Research Ethics Committee of University of Ibadan/University College Hospital, Ibadan, Nigeria, with a reference number UI/UCH EC: NHREC/05/01/2008a.

\section{Informed Consent}

Subjects for this study were adults who were adequately briefed on the research protocol and informed consent was obtained prior to sample collection. The informed consent form used for this study was clearly explained to the participants in English and in their native language.

\section{Sample collection}

Five millilitres $(5 \mathrm{ml})$ of venous blood was collected from the cubital fossa of the research participants into Tripotassium Ethylene Diamine Tetraacetic Acid (K $\mathrm{K}_{3}$ EDTA) anticoagulant container. Verbal informed consent was used in bringing the subjects to the knowledge of the 
exercise, this was followed by the administration of simplified questionnaires to each of the participants. The research subjects were placed in two groups: the test group comprised sixty-three (63) individuals who were occupationally exposed to e-wastes for a minimum of five (5) days a week and eight (8) hours per day, while the control group comprised forty-one (41) e-waste naive males. All the research participants were males between the ages of twenty (20) and sixty-five (65) years and were recruited from the University of Benin Community. The blood samples were analysed within six hours of collection.

\section{Determination of heavy metal levels in blood}

Plasma iron and blood lead levels were determined in the analytical services laboratory of the International Institute for Tropical Agriculture, IITA, Ibadan, using the inductively coupled plasma mass spectrometer (ICP-MS) (Thermo Elemental, X series I, Germany), based on standard methods [18].

\section{Determination of haematological parameters}

The Automated Haematology Analyzer (Sysmex KX - 21N; Kobe, Japan) was used to analyze all haematological parameters such as WBC ( $\mu 1)$, LY (\%), MO (\%), GR (\%), RBC ( $\mu 1), \operatorname{Hgb}(\mathrm{g} / \mathrm{dl})$, HCT (\%), MCV (fl), MCH (pg), MCHC (g/dl) and PLT ( $\mu \mathrm{l})$ based on standard methods [19] and following the manufacturer's operational guidelines. All samples were analyzed within 30 minutes of collection.

\section{Statistical Analysis}

Statistical analyses including descriptive statistics was carried out using the Statistical Package for Social Scientists (SPSS) version 16.0. All values were expressed as Mean \pm Standard Error of the Mean. The Independent Student's t-test was used to determine significant differences between exposed and unexposed groups and $p$ value $<0.05$ was accepted. 


\section{Results}

Table 1 shows the serum levels of iron and lead in e-waste exposed and unexposed participants. The mean serum iron and lead levels were significantly elevated in the exposed subjects when compared with their unexposed counterparts.

Table 2 shows the haematological parameters of the exposed and unexposed groups. The total White Blood Cell (WBC), Red Blood Cell (RBC), and Monocyte (MO) counts, as well as the haematocrit (HCT) and Mean Cell Volume (MCV) were all significantly elevated in the exposed group when compared with their controls. On the other hand, the Haemoglobin (Hgb) concentration, Mean Cell Haemoglobin Concentration (MCHC), Lymphocytes (LY), and Platelets (PLT) were all significantly depressed in the exposed group when compared with their unexposed counterparts.

Table 1: Serum iron and lead levels in e-waste exposed and unexposed participants

\begin{tabular}{llclll}
\hline Metals & $\begin{array}{c}\text { Exposed } \\
\text { Participants } \\
(\mathbf{n}=63)\end{array}$ & $\begin{array}{c}\text { Unexposed } \\
\text { Participants } \\
(\mathbf{n}=\mathbf{4 1})\end{array}$ & t-value & p-value & $\begin{array}{l}\text { Level of } \\
\text { significance }\end{array}$ \\
\hline Iron $(\mu \mathrm{g} / \mathrm{dL})$ & $11.5 \pm 2.14$ & $168.9 \pm 2.39$ & 0.000 & 0.007 & $\begin{array}{l}\text { Highly } \\
\text { significant }\end{array}$ \\
\hline Lead(ug/dL) & $0.95 \pm 0.00$ & $0.03 \pm 0.00$ & 19.26 & 0.000 & $\begin{array}{l}\text { Highly } \\
\text { Significant }\end{array}$ \\
\hline
\end{tabular}

Values are expressed as means \pm SEM. 
Table 2: Haematological parameters in exposed and unexposed participants.

\begin{tabular}{|c|c|c|c|c|}
\hline $\begin{array}{l}\text { Haematological } \\
\text { Parameter }\end{array}$ & $\begin{array}{l}\text { Exposed } \\
\text { Participants } \\
\quad(n=63)\end{array}$ & $\begin{array}{l}\text { Unexposed } \\
\text { Participants } \\
\quad(n=41)\end{array}$ & p-value & Level of significance \\
\hline TWBC $\times 10^{3} /$ ul & $5.27 \pm 0.17$ & $4.09 \pm 0.19$ & $\mathrm{P}<0.001$ & Highly significant \\
\hline Lymphocytes (\%) & $31.10 \pm 1.69$ & $42.04 \pm 2.27$ & $\mathrm{P}<0.001$ & Highly significant \\
\hline Monocytes (\%) & $13.45 \pm 0.54$ & $12.71 \pm 1.24$ & $\mathrm{P}<0.05$ & Significant \\
\hline Granulocytes (\%) & $55.42 \pm 1.89$ & $43.99 \pm 2.22$ & $\mathrm{P}<0.001$ & Highly significant \\
\hline Platelets $\times 10 / \mathbf{u l}$ & $130.94 \pm 5.52$ & $228.89 \pm 13.17$ & $\mathrm{P}<0.001$ & Highly significant \\
\hline $\mathrm{RBC} \times 10^{6} / \mathrm{ul}$ & $5.58 \pm 0.06$ & $5.30 \pm 0.07$ & $\mathrm{P}<0.01$ & Highly significant \\
\hline $\begin{array}{l}\text { Haemoglobin } \\
\text { Concentration (g/dl) }\end{array}$ & $15.11 \pm 0.16$ & $16.36 \pm 0.16$ & $\mathrm{P}<0.001$ & Highly significant \\
\hline $\operatorname{PCV}(\%)$ & $46.35 \pm 0.41$ & $50.87 \pm 10.73$ & $\mathrm{P}<0.001$ & Highly significant \\
\hline $\operatorname{MCV}$ (fl) & $83.11 \pm 0.61$ & $75.94 \pm 1.26$ & $\mathrm{P}<0.001$ & Highly significant \\
\hline MCH (pg) & $28.26 \pm 1.13$ & $30.91 \pm 0.39$ & $\mathrm{P}>0.05$ & Not Significant \\
\hline $\operatorname{MCHC~(g/dl)~}$ & $32.47 \pm 0.23$ & $41.03 \pm 0.83$ & $\mathrm{P}<0.001$ & Highly significant \\
\hline
\end{tabular}

Note: Values are in mean \pm Standard Error of Mean 


\section{Discussion}

The scourge of electronic waste (e-waste) is currently a major global concern, particularly in developing countries like Nigeria where e-waste reprocessing is substantial and unregulated. Recently, researchers have become more interested in the toxicity of electronic waste components, especially as a result of their heavy metal content [20]. The present study investigates the adverse health effects of lead toxicity on iron status, and the hematopoietic system in individuals occupationally exposed to electronic waste.

Lead has been regarded as a potent occupational toxin and its toxicological manifestations are well known. There is no such level of lead that appears to be beneficial to the human body and no "safe" level of exposure of lead has been found. Lead toxicity is a hazard with the potential of causing irreversible health effects and known to interfere with a number of body functions, primarily affecting the haematopoietic, central nervous, hepatic and renal systems producing serious disorders [21].

The highly significant depression of serum iron $(\mathrm{Fe})$ in the test group relative to their controls suggests an established impairment of iron absorption as a result of lead toxicity. Lead is a particularly pernicious element to iron metabolism, as it is taken up by the iron absorption machinery, and secondarily blocks iron through competitive inhibition. It therefore interferes with a number of important iron dependent metabolic steps such as heme biosynthesis [22].

In the same vein, the haemoglobin concentration and MCHC were significantly lower in the test group when compared with the control subjects. This observation is likely a consequence of lead interaction with heme synthesis. Lead significantly affects the heme synthetic pathway in a dose 
dependent manner by downregulating three key enzymes involved in the synthesis of heme, d-aminolevulinic acid dehydratase, aminolevulinic acid synthetase and ferrochalatase [23].

Conversely, the total RBC and MCV were significantly elevated in the test group as compared to the non-exposed. This increase may be due to a physiological compensatory mechanism wherein the haematopoietic machinery synthesizes new red cells (reticulocytosis) in order to adequately compensate for damaged red cell which may be as a result of lead-induced haematotoxicity. Previous studies have shown that lead is a potential trigger for megaloblastic anaemia by impairing heme synthesis, reducing the life span of circulating erythrocytes (due to cell membrane fragility) and thereby increasing the rate of RBC destruction [24].

The mean haematocrit value was significantly depressed in the test group relative to their controls. This observed difference in the Packed Cell Volume (PCV) is suggestive of acute haemolytic anaemia in the test group. According to Vij, anaemia caused on account of lead poisoning can be of two types: haemolytic anaemia, which is associated with acute high-level lead exposure and frank anaemia, which is caused only when the blood lead level is significantly elevated for prolonged periods [25].

Furthermore, the mean total WBC count of the participants showed a significant increase in the test group relative to their controls. Cells of the innate immune mechanism usually mount their immune responses against harmful foreign agents that gained access to the body. Reports from previous authors speculate that increased number of circulating neutrophils may represent a mechanism to compensate lead-mediated immune dysfunction, which is more likely to reflect a neuroendocrine response to toxicity/stress. Farkhondeh also observed and concluded that inhaled 
lead can increase IgE, histamine levels, total and most differential WBC counts in sensitized animals exposed to lead [26].

Similarly, the mean lymphocytes value observed in the test group was significantly lower than that seen in their control counterparts. Reports have suggested that exposure to lead affects humoral immune response, functional impairment of lymphocytes and production of cytokines [27]. It is also well established that lead affects humoral and cell mediated immunity, and diminishes host resistance [28]. It can therefore be inferred that the significant decrease in lymphocytes of the test group may be as a result of occupational exposure to toxic lead fumes.

Furthermore, the mean platelet count was also found to be markedly depressed in the test group relative to their controls. Barman and colleagues have reported that chronic occupational exposure to lead may depress platelet counts, thus suggesting that lead exposure may impair coagulation function through endothelial tissue injury and reduction of nitric oxide [29]. From the foregoing, it can therefore be induced that chronic occupational exposure to lead can result to lead-induced thrombocytopenia.

\section{Conclusion}

Chronic occupational e-waste exposure may increase blood lead level, lower serum iron status and may have adversely altered some important haematological parameters in the studied population. 


\section{References}

1. Nnorom I.C., Ohakwe J, and Osibanjo O. Survey of willingness of residents to participate in electronic waste recycling in Nigeria. A case study of mobile phone recycling. Journal of Cleaner Production 17 2009; 1629-1637.

2. Balde CP, Kuehr,R, Blumenthal K, Gill KSF , Kern M, Micheli P, Magpantay E and Huisman J. E-waste statistics: Guidelines on classifications, reporting and indicators. United Nations University, IAS - SCYCLE, Bonn, Germany. 2015.

3. Agency for Toxic Substances and Disease Registry (ATSDR). Toxicological profile for lead, Update. Prepared by Clement International Corporation under contact no.205-88-060 for ATSDR, U.S. Public Health Services, Atlanta, GA 1993

4. Leonard SS, Harris GK and Shi X. Metal-induced oxidative stress and signal transduction. Free Rad. Biol. Med. 2004; 37: 1921-1942.

5. Noori S. An overview of oxidative stress and antioxidant defensive system. Scien. Reports 2012; 1(8): 413-422.

6. Ercal N, Gurer-Orphan H and Aykin-Burns N. Toxic metals and oxidative stress part I: Mechanism involved in metal induced oxidative damage. Curr. Topics Med. Chem. 2001; 1: $529-539$.

7. Igharo OG, Anetor JI, Osibajo OO, Osadolor HB, David OM and Agu KC. Oxidative stress and antioxidant status in Nigerian E-waste workers: A cancer risk predictive study. Bri. Jour. Med. Medical Res. 2016; 13(2): 1-11.

8. Salomon RG, Kaur K, Podrez E, Hoff HF, Krushinsky AV and Sayre LM. HNE- derived 2-pentylpyrroles are generated during oxidation of LDL, are more prevalent in blood plasma from patients with renal disease or atherosclerosis, and are present in atherosclerotic plaques. Chem. Res. Toxico. 2000;13: 557-564.

9. Eichhorn GL, Shin YA. Interaction of metal ions with polynucleotides and related compounds. XII. The relative effect of various metal ions on DNA helicity. Jour. Amer. Chem. Soc. 1968; 90(26): 7323-7328. 
10. Swaran, J.S. and Vidhu P. Chelation in Metal Intoxication. Intern. Journ. Environ. Res. Public Health. 2010; 7: 2745-2788.

11. Elayat, W., and Bakheetf, M. S. Effects of chronic lead toxicity on liver and kidney functions. J Med Lab Sci 2010; 1: 29-36.

12. Mugahi, M. N., Heidari, Z., Sagheb, H. M. and Barbarestani, M. Effects of chronic lead acetate intoxication on blood indices of male adult rat. DARU Jour. Pharm. Sci. 2003; 11: $147-151$.

13. Suradkar, S. G., Ghodasara, D. J., Patel, J., Jaiswal, V. and Prajapati, K. S. Haemato-Biochemical alterations induced by lead acetate toxicity in wistar rats. Veter. World 2009; 2: 429-431

14. Ahrens, F.A. Eefects of lead on glucose metabolism, ion flux, and collagen synthesis in cerebral capillaries of calves. Amer. Jour. Veterin. Res 1993; 54: 808-812.

15. Pitot, C. H., and Dragan, P. Y. Chemical carcinogenesis. Casarett and Doull's toxicology. 5th ed.New York: McGraw Hill 1996: Pp 201-260.

16. Lynch, S. R. Overview of the relationship of iron to health. Contemp. Nutri 1994; 19: 4-5.

17. Adaramodu AA, Osuntogun BA, Ehi-Eromosele CO. Heavy Metal Concentration of Surface Dust Present in E-waste Components: The Westminister Electronic Market, Lagos Case Study. ARPN Journal of Science and Technology 2 (Special Issue) 2012; 247-270

18. Fong BMW, Siu TS, Lee JSK, Tam S. Determination of Mercury in Whole Blood and Urine by Inductively Coupled Plasma Mass Spectrometry. Jour. Analyt. Toxico 2007; 31 : $281-287$.

19. Cheesborough, M. District Laboratory Practice in Tropical Countries. Cambridge University Press; New York 2006: 299-325.

20. Igharo GO, Anetor JI, Osibanjo OO, Osadolor HB and Dike K. Toxic metal levels in Nigerian electronic waste workers indicates occupational metal toxicity associated with crude electronic waste management practices. Biokemistri 2014; 26(4): 107-113. 
21. Kalia, K. and Flora, S.J. Strategies for safe and effective therapeutic measures for chronic arsenic and lead poisoning. Jour. Occup. Health 2005; 47:1-21.

22. Goyer, R. A. Lead toxicity Current concerns. Environ. Health. Prosp 1993;100: 177-187

23. Piomelli, S. Childhood lead poisoning. Pediatr. Clin. North. Amer 2002; 49:1285-1304.

24. Guidotti, T.L. and Ragain, L. Protecting children from toxic exposure: three strategies. Pediatr. Clin. North. Amer 2007; 54:227-235

25. Vij, A.G. Hemopoietic, hemostatic and mutagenic effects of lead and possible prevention by zinc and vitamin C. Al Ameen. Journ. Med. Sci 2009;2:27-36

26. Demirezen, D. and Kadiriye, U. Comparative study of trace elements in certain fish, meat and meat production. Meat. Sci 2006;74: 255-260.

27. Dyatlov, V.A., Lawrence, D.A. Neonatal lead exposure potentiates sickness behavior induced by Listeria monocytogenes infection of mice. Brain. behav. Imm 2002; 16(4):477-492.

28. McCabe, J.B., and Berthiaume, L.G. Functional roles for fatty acylated amino-terminal domains in subcellular localization. Mol. Bio. Cell 1999; 10(11):3771-86.

29. Barman T.1., Kalahasthi, R.1., and Rajmohan, H.R.1. Effects of lead exposure on the status of platelet indices in workers involved in a lead-acid battery manufacturing plant. Jour. Exp. Sci. Environ. Epidemio 2014; 24(6):629-633. 